Journal of Animal and Veterinary Advances $10(6)$ : 802-805, 2011

ISSN: $1680-5593$

(C) Medwell Journals, 2011

\title{
Efficacy of Different Organic Compounds Against Bee Mite (Varroa destructor Anderson and Trueman) in Honey Bee (Apis mellifera L.) Colonies
}

\author{
Berna Emsen and Ahmet Dodologlu \\ Department of Animal Science, Ataturk University, 25240 Erzurum, Turkey
}

\begin{abstract}
In the present study, two organic compounds (thymol and oxalic acid) were used to treat colonies against Varroa destructor with three delivery methods. The compounds were applied alone or in combination and the results were correlated with climatic variables (temperature and humidity). We investigated the efficacy of organic products which were applied as dust, diluted in sugar syrup trickled onto the bees and dissolved in ethanol embedded in vermiculite blocks. The best results were obtained with thymol applied in dust $(89.98 \%)$ and in vermiculite $(77.15 \%)$. The lowest efficacies were those of the oxalic acid treatments $(<50 \%)$. There was a positive correlation between temperature and mite mortality for the thymol in dust and for the thymol in vermiculite methods $(r=0.73$ and $r=0.71$, respectively). Conversely, a negative correlation was found between humidity and mite mortality for thymol applied in dust $(\mathrm{r}=-0.71)$. Mite mortality in oxalic acid treatments did not show significant correlation with climatic variables, except when combined with thymol and applied in vermiculite blocks $(\mathrm{r}=0.70)$. This result indicates that thymol in dust and in vermiculite methods are effective alternative fall treatments for varroa mites.
\end{abstract}

Key words: Varroa destructor, honey bee, thymol, oxalic acid, efficiency, climatic effects

\section{INTRODUCTION}

The mite Varroa destructor (Anderson and Trueman, 2000), a parasite of Apis mellifera has to be controlled by the regular use of acaricides in order to maintain honeybee colonies. About $>140$ hard chemical products were used in many countries and the mite had showed a resistance to synthetic miticides such as coumaphos, amitraz, fluvalanite and flumethrin (Elzen et al., 2000). These hard chemicals have the disadvantage of leaving residues in honey and wax being a hazard to handle, having some level of toxicity to bees and humans and also because mites quickly develop resistance to their active ingredient (Bogdanov et al., 1998). On the other hand, the use of organic compounds such as thymol and oxalic acid has been tested to control varroa infestations in honey bee colonies.

Thymol which is a volatile monoterpenoid is a natural constituent of thyme (Thymus vulgaris) and is toxic to varroa mites (Lindberg et al., 2000). The efficacy of thymol has been tested in previous studies and recommended that the product is a well known effective compound against the varroa infection which can be used in place of chemical treatments such as coumaphos and amitraz (Gregorc and Planinc, 2004; Espinosa-Montano and Guzman-Novoa, 2007). The use of oxalic acid as a means of controlling varroa mite infestations in colonies has been studied extensively (Gregorc and Planinc, 2001).
Thymol and oxalic acid which belong to the alternative mite control strategy could be used successfully (Imdorf et al., 2003). There are a number of factors known to affect treatment efficacy. Factors such as the amount of brood in the hive (Eischen, 1998), time of year (Maul et al., 1980), temperature, humidity (Skinner et al., 2001), colony size and conditions have also been suggested to affect treatment efficacy. However, little research has been conducted on developing efficient application methods aimed to increase efficacy as well as to reduce its dependency on climatic factors. Little is known about how oxalic acid is distributed in honey bee colonies. A better understanding of how oxalic acid is distributed in honey bee colonies is critical to designing rational delivery systems.

In the experiment, we evaluated the efficacy of thymol and oxalic acid applied with three different delivery methods, alone and in combination to control $V$. destructor infestations in honey bee colonies during early fall. Moreover, we analyzed the effects of temperature and humidity on the efficacy of the different delivery method systems.

\section{MATERIALS AND METHODS}

The experiment was carried out in an apiary of 50 colonies of bees at the Ataturk University located in central Erzurum and colonies were placed in Langstroth

Corresponding Author: B. Emsen, Department of Animal Science, Ataturk University, 25240 Erzurum, Turkey 
hives. The colonies were initially equalized to contain a similar amount of brood $\left(2992.343 \pm 57.67 \mathrm{~cm}^{2}\right)$, bee population (ca. 8 frames covered with bees) and food stores ( 2 combs containing honey and pollen). Colonies were managed in the same way until the miticide trails initiated.

The experimental colonies showed low levels of infestation of $<1$ mite in $24 \mathrm{~h}$ using a sticky paper under a screened bottom board; colonies were artificially infested with ca. 100 mites each. In order to infest the colonies, 50 workers of each colony were confined in 2 Benton queen cages and 1 adult female of $V$. destructor was placed on the body of each worker with a fine brush. The cages with the infested workers were re-introduced into their respective colony so that the infested bees could be released by the workers of their colony. The mites used to infest the experimental colonies came from several highly infested colonies located away from the experimental apiaries. To collect the mites, a $19 \mathrm{~L}$ plastic container which had a $4 \mathrm{~mm}$ wire mesh screen $20 \mathrm{~cm}$ above its bottom was used. Between the bottom of the container and the screen, two $40 \mathrm{~mL}$ vials half-filled with ether were placed. Workers of the infested colony were shaken into the container that was then closed for $5 \mathrm{~min}$ to anaesthetize the bees and to allow the mites to fall off of the workers. Then the mites were collected from the bottom of the container.

Colonies were treated with the above combination of product/delivery method as follows: Treatment 1 consisted of thymol applied weekly with the Trickled method (TT). A thymol/sugar syrup solution was prepared from $6 \mathrm{~g}$ thymol and $100 \mathrm{~mL}$ sugar syrup. This solution was trickled onto the bees located at the 4 central frames of each hive, trying to cover as much area and bees as possible. Treatment 2 consisted of thymol applied weekly with the dust method (TD); $6 \mathrm{~g}$ of powdered thymol (grinded crystals) was mixed with $24 \mathrm{~g}$ confectionary sugar. About $30 \mathrm{~g}$ layer of this mix was spread over the surface of a half newspaper sheet. A half paper sheet was placed over the frames of the brood chamber of each colony every week for 4 weeks. Treatment 3 consisted of thymol applied weekly with the vermiculite method (TV). The blocks of vermiculite were used for this treatment. A piece of vermiculite block $5 \times 7.5 \times 0.7 \mathrm{~cm}$ was treated with $10 \mathrm{~mL}$ of a $20 \%$ thymol solution in alcohol ( $10 \mathrm{~mL}$ of alcohol and $2 \mathrm{~g}$ of thymol) and injected into one vermiculite block. Two of these blocks were placed over the center of the brood chamber in each colony between the frames 3 and 7 . Treatments 4-6 were also applied weekly and consisted of the three methods of delivery described above, respectively but using oxalic acid instead of thymol. The amount of oxalic acid was $2 \mathrm{~g}$ diluted in $100 \mathrm{~mL}$ sugar syrup for treatment 4 (OT). About $2 \mathrm{~g}$ of the product mixed with $28 \mathrm{~g}$ of powdered sugar for treatment $5(\mathrm{OD})$ and $2 \mathrm{~g}$ of oxalic acid dissolved in $10 \mathrm{~mL}$ of alcohol for treatment $6(\mathrm{OV})$. Treatments 7-9 were applied as above but using a mixture of thymol and oxalic acid. The doses of mixture of thymol and oxalic acid were used previously mentioned for thymol and oxalic acid ( $6 \mathrm{~g}$ of thymol plus $2 \mathrm{~g}$ of oxalic acid/colony; TOT, TOD and TOV). All treatments applied weekly during 4 occasions. Treatment 10 was composed of control hives that did not receive any chemical treatment. Control Colonies (CC) received $100 \mathrm{~mL}$ sugar syrup trickled on the bees, $30 \mathrm{~g}$ of powdered sugar and two dry vermiculite blocks.

The degree of effectiveness of the treatments tested was determined by their percentage of control in relation to the synthetic miticide coumaphos (Perizin $\left.{ }^{\circledR}\right)$. At the end of the 4th week of the experimental trials, each colony was treated with three Perizin ${ }^{\circledR}$ treatments according to the instructions of the manufacturer. The percent efficacy of each treatment was calculated by dividing the number of mites that fell during the period of experimental treatment, by the total number of mites (mite drop of experimental and finisher treatment with Perizin ${ }^{\circledR}$ ). The resulting figure was then multiplied by 100 .

Temperature and humidity readings were recorded daily throughout the course of the experiments. Maximum, minimum and average temperature and humidity data were noted. Measures of ambient temperature and relative humidity were examined to assess their effects on the efficacy of the different treatments with three delivery methods applied.

Data on percent efficacy were analyzed by Analysis of Variance (ANOVA) after (arcsine $\sqrt{\mathrm{y}} / 100$ ), arcsine transformation in the case of percentages, to reduce the heterogeneity of the variance. Means were separated applying the Duncan test $(\mathrm{p}<0.05)$. Data on number of falling mites were analyzed with Mann-Whitney $U$ tests to compare periods and treated vs. control colonies. Nonparametric methods were used because these data were not normally distributed. Climatic data (ambient temperature and R.H.) were $\log$ transformed and correlated with mite fall using Pearson correlation analyses (Sokal and Rohlf, 1981).

\section{RESULTS}

Mite levels in colonies were not different among the treatment groups prior to the application of treatments $\left(46.92 \pm 6.6 ; \mathrm{F}_{9,40}=0.42 ; \mathrm{p}=0.92\right)$. The number of mites that fell in all of the treated colonies was significantly higher than that of control colonies $\left(F_{9,40}=11.8, p<0.01\right)$. The 


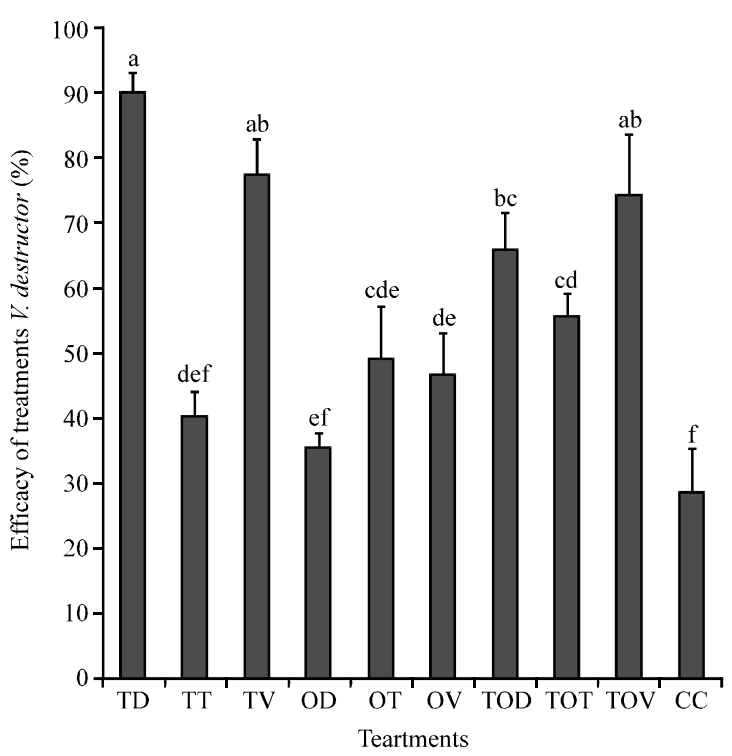

Fig. 1: Efficacy of treatments against V. destructor infestation. ${ }^{\mathrm{a}-\mathrm{f}}$ Means with the same letters are not significantly different $(\mathrm{p}<0.01)$

miticide efficacy of the TD method $(89.98 \pm 2.9 \%)$ was not different to that of the TV method $(77.15 \pm 4.9 \%)$ and TOV (74.08 $19.3 \%$ ) but the former treatment showed a significantly higher percent efficacy than the rest of the treatments. The lowest efficacy was obtained in group of OT and not different to that of control (Fig. 1). Additionally, no synergic effect was found when thymol and oxalic acid were applied combined. The percent efficacy in combined treatments didn't show higher percent efficacy than that of other treatments (Fig. 1).

A positive correlation was found between temperature and mite fall for the TD and TV methods $(\mathrm{r}=0.73, \mathrm{p}<0.05 ; \mathrm{r}=0.71, \mathrm{p}<0.05$, respectively, $\mathrm{n}=5$ ). Conversely, a negative correlation was found between R.H. and mite drop for the TD $(\mathrm{r}=-0.71, \mathrm{p}<0.05, \mathrm{n}=5$ in both cases). Mite fall did not correlate with temperature or R.H. for the TT method. Mite fall from oxalic acid treatments did not show correlation with climatic variables, except for the TOV method in which mite fall correlated with temperature $(\mathrm{r}=0.70, \mathrm{p}=0.05, \mathrm{n}=5)$.

\section{DISCUSSION}

Treatments effects on varroa mite mortality were significant in colonies. The differences were found significantly important $(\mathrm{p}<0.01)$ between thymol and oxalicacid. Thymol in dust and in vermiculite treatments showed the highest efficacy against varroa control. In the study, the result of mite mortality averaged $89.98 \%$ in colonies receiving the thymol-dust was higher than the findings, 83.15 and $75.4 \%$ reported by Emsen et al. (2007), Calderone (2000), respectively. The levels of varroa mite control found here using thymol in dust were similar to that reported by Lindberg et al. (2000) but lower than the finding 92\% used thymol in gel (Espinosa-Montano and Guzman-Novoa, 2007).

The variability in treatments efficacy found in previous studies with thymol in vermiculite application was higher in the experiment. When thymol applied in vermiculite blocks, its efficacy was recorded $35 \%$ control of varroa mites which is lower than the result (Whittington et al., 2000). The results of different researchers suggest that application of thymol can be effectively used as an alternative $V$. destructor control.

The efficacy of oxalic acid was not effective alone to control varroa destructor. Neither oxalic acid with trickle, oxalic acid with vermiculite nor oxalic acid with in dust was significantly different. The result of oxalic acid treatments investigated in previous experiments was also evident in the studies (Gregorc and Planinc, 2001; Brodsgaard et al., 1999).

Concerning the number of mites on the sticky paper, similar results were obtained by the application methods in the experiment were found dependent on temperature and R.H. In a previous study, there was a positive significant correlation between temperature and mite drop (Caldorene and Nasr, 1999). On the contrary this result, Stanghellini and Raybold (2004) reported that there was no any relationship between temperature and mite drop.

\section{CONCLUSION}

In the study, thymol-dust and thymol-vermiculite treatments are suggested that as shorter applications interval and the most effective method by the finding from the present study to control varroa mite. It could be recommended to beekeepers to apply thymol-dust in warmer days. It could also be expected that thymol in dust will work better in warm and dry regions than in cold and humid regions.

\section{REFERENCES}

Anderson, D.L. and J.W.H. Trueman, 2000. Varroa jacobsoni (Acari: Varroidae) is more than one species. Exp. Applied Acarol., 24: 165-189.

Bogdanov, S., A. Imdorf and V. Kilchenmann, 1998. Residues in wax and honey after ApiLife VAR treatment. Apidology, 29: 513-524. 
Brodsgaard, C.J., S.E. Jensen, C.W. Hansen and H. Hansen, 1999. Spring treatment with oxalic acid in honeybee colonies as Varroa control. DIAS Rep. Horticul., 6: 1-16.

Calderone, N.W., 2000. Effective fall treatment of Varroa jacobsoni (Acari: Varroidae) with a new formulation of formic acid in colonies of Apis mellifera (Hymenoptera: Apidae) in the northeastern United States. J. Econ. Entomol., 93: 1065-1075.

Caldorene, N.W. and M.E. Nasr, 1999. Evaluation of formic acid formulation for the fall control of Varroa jacobsoni (Acari: Varroidae) in colonies of honey bee Apis mellifera (Hymenoptera: Apidae) in a temperate climate. J. Econ. Entomol., 92: 526-533.

Eischen, F.A., 1998. Trials and tribulations with formic acid for Varroa control. Amer. Bee J., 138: 734-735.

Elzen, P.J., J.R. Baxter, M. Spivak and W.T. Wilson, 2000. Control of Varroa jacobsoni Oud. resistant to fluvalinate and amitraz using coumaphos. Apidologie, 31: 437-441.

Emsen, B., E. Guzman-Novoa and P.G. Kelly, 2007. The effect of three methods of application on the efficacy of thymol and oxalic acid for the fall control of the honey bee parasitic mite Varroa destructor in a northern climate. Am. Bee J., 147: 535-539.

Espinosa-Montano, L.G. and E. Guzman-Novoa, 2007. Effectiveness of two natural miticides, formic acid and thymol, for control of the mite Varroa destructor in honey bees (Apis mellifera L.) in Villa Guerrero. Mexico. Vet. Mex., 38: 9-19.

Gregorc, A. and I. Planinc, 2001. Acaricidal effect of oxalic acid in honeybee (Apis mellifera) colonies. Apidologie, 32: 333-340.
Gregorc, A. and I. Planinc, 2004. Dynamics of falling varroa mites in honeybee (Apis mellifera) colonies following oxalic acid treatments. Acta. Vet. Brno, 73: $385-391$.

Imdorf, A., J.D. Charriere, V. Kilchenmann, S. Bogdanov and P. Fluri, 2003. Alternatif strategy in central Europe for the control of Varroa destructor in honey bee colonies. Apiacta, 38: 258-285.

Lindberg, C.M., A.P. Melathopoulos and M.L. Winston, 2000. Laboratory evaluation of miticides to control Varroa jacobsoni (Acari: Varroidae), a honey bee (Hymenoptera: Apidae) parasite. J. Econ. Entomol., 93: 189-198.

Maul, V., M. Petersen and W. Wissen, 1980. Field trials using formic acid as a varroatosis threapy. Algemeine Deutsche Imkerzeitung, 14: 155-157.

Skinner, J.A., J.P. Parkman and M.D. Studer, 2001. Evaluation of honey bee miticides, icluding temporal and thermal effects on formic acid gel vapours, in the central south-eastern USA. J. Apicult. Res., 40: 81-89.

Sokal, R.R. and F.J. Rohlf, 1981. Biometry. W.H. Freeman and Co., New York, USA., pp: 859.

Stanghellini, M.S. and P. Raybold, 2004. Evaluation of selected biopesticides for the late fall control of varroa mites in a Northern temperate climate. Am. Bee. J., 144: 475-480.

Whittington, R., M.L. Winston, A.P. Melathopolus and H.A. Higo, 2000. Evaluation of the botanical oils neem, thymol and canola sprayed to control Varroa jacobsoni Qud. (Acari: Varroidae) and Acarapis woodi (Acari: Tarsonemidae) in colonies of honey bee (Apis mellifera L., Hymenoptera: Apidae). Am. Bee J., 140: 567-572. 